RU Основные принципы обучения английскому языку студентов пожилого возраста в рамках концепции “Lifelong Learning”

\begin{abstract}
Иванова А. М., Малыгина Е. В., Федорова Е. Д.
Аннотация. В статье рассматриваются некоторые методические особенности преподавания английского языка людям «серебряного возраста» на базе высших учебных заведений. Целью исследования является формирование основных принципов данной педагогической практики и влияющих на них возрастных и психологических особенностей пожилых людей, а также выбор актуального содержания учебной программы. Научная новизна состоит в определении ключевых критериев содержания курсов английского языка для людей пенсионного возраста, также приводятся конкретные примеры реализации программы на занятиях для пожилых москвичей. В результате авторы приходят к заключению, что преподавание иностранного языка в рамках концепции непрерывного образования должно следовать четырем ключевым методическим принципам - аппроксимации, релевантности, цикличности и доступности.
\end{abstract}

\title{
The Basic Principles of Teaching English to Elderly Students within the Framework of "Lifelong Learning"
}

\author{
Ivanova A. M., Malygina E. V., Fyodorova E. D.
}

\begin{abstract}
The article considers methodological peculiarities of teaching English to "third age" students on the basis of higher education institutions. The research objectives are as follows: to reveal the basic methodological principles of teaching this age group taking into account age-related and psychological features of elderly people, to develop a methodological approach to choosing relevant content of the educational program. Scientific originality of the study involves identifying the basic criteria for choosing the content of the English-language course for "third age" people. The paper provides examples of exercises used in English classes for elderly Muscovites. The authors conclude that foreign language teaching within the framework of "Lifelong Learning" should be based on four methodological principles - approximation, relevance, cyclicity and availability.
\end{abstract}

\section{Введение}

Непрерывное образование - концепция XXI века, возникшая в условиях стремительного накопления знаний, обновления и конвергенции технологий и размывания границ между отраслями. Данный тип мышления подразумевает, что определяющим фактором инновационного развития государства становится экономика, основанная на знаниях (knowledge-based economy / information economy), и человеческий капитал (human capital) [1; 25], а именно наличие достаточного количества качественно подготовленных специалистов, готовых осуществлять интеллектуальную деятельность и своевременно решать актуальные проблемы в различных сферах науки, производства и общественной жизни. Вследствие ускорения научного и технического прогресса, полученных в молодости знаний и способностей (несмотря на увеличение продолжительности начального, среднего и высшего образований) чаще всего оказывается недостаточно для успешной профессиональной карьеры на протяжении трёх или четырёх десятилетий. Развитие непрерывного образования взрослых в Российской Федерации заявлено как заказ со стороны государства и общества [20], образовательные организации и бизнес-структуры активно поддерживают установку на то, что получение новых профессиональных и иных компетенций возможно в любом возрасте. 
Концепция непрерывного образования в течение жизни (Lifelong Learning) отражена в Федеральном законе от 29 декабря 2012 г. № 273-ФЗ «Об образовании в Российской Федерации» и предполагает создание широких возможностей для приобретения необходимых квалификаций на протяжении всей трудовой деятельности взрослого населения, условий для повышения функциональной грамотности взрослого населения, а также развитие инфраструктуры и технологий сферы непрерывного образования для обеспечения личностного роста и самореализации различных категорий взрослого населения, включая пожилых людей [12, с. 7]. Особенности реализации концепции непрерывного образования в российских образовательных учреждениях рассматриваются в значительном количестве теоретических работ (см., например, [9; 19; 24] и др.), но акцент преимущественно делается на важности обеспечения непрерывного профессионального образования, начинающегося в стенах университета и заканчивающегося достижением пенсионного возраста. Таким образом, исследователи оставляют за рамками «третий возраст», хотя пожилые граждане также могут быть заинтересованы в профессиональной переподготовке [10]. Несомненным шагом вперед, который делают некоторые исследователи, является признание частью концепции Lifelong Learning не только формальных программ последипломного образования, позволяющих повысить квалификацию, улучшить профессиональные навыки или пройти профессиональную переподготовку, но и разнообразных практик самообразования [5; 13] и саморазвития [22; 23], не ограниченных возрастными рамками. Практики саморазвития - работа над улучшением своих личностных качеств и навыков, не связанных с профессиональной деятельностью индивида, но необходимых ему для достижения каких-либо личных целей, - как представляется, приобретают особую актуальность для людей пожилого возраста, уже не являющихся частью рынка труда, но стремящихся оставаться активными, осваивать современные технологии и по возможности реализовать свой потенциал в какой-либо представляющей интерес сфере.

В контексте Lifelong Learning изучение иностранного языка в пожилом возрасте приобретает особую актуальность в качестве темы исследования. Данную деятельность можно рассматривать как продолжение развития коммуникационных навыков, полученных когда-то в стенах школы и университета, при этом следует отметить отсутствие сколько-либо значительного количества теоретических и теоретико-методических работ на данную тему (см., например, [6; 7; 14], где некоторые методические принципы обучения пожилых людей основам иноязычной речи описываются без детализации под конкретный язык). Исследователи отмечают предпочтительные методы работы с учащимися «третьего возраста». Так, И. В. Высоцкая высказывает мнение о том, что наиболее эффективным методом освоения языковой компетенции является вовлечение возрастных учащихся в процесс обучения через использование ролевых игр и других коммуникативных заданий (опрос, интервью, дискуссия и т.д.), тогда как общие методические принципы преподавания иностранных языков пожилым людям сформулированы недостаточно конкретно, как «коммуникативные, биографические и межпоколенческие» [7, с. 57]. Е. Г. Калинина [14], а также Л. С. Афанасьева и Т. В. Савина [6] в качестве основополагающих принципов называют непрерывную коммуникацию на языке на занятиях и наличие визуально-вспомогательных средств и материалов для аудирования, что представляется необходимым условием для курсов иностранного языка для любой возрастной аудитории.

Люди пенсионного возраста, с одной стороны, стремятся изучать английский язык в целях саморазвития (часто как способ стимуляции когнитивных функций или знакомства с интересной культурой), необязательно в практическом ключе. С другой стороны, обучение иностранному языку может иметь исключительно прикладной смысл - для поездок за границу и общения в межкультурной среде. При таком «утилитарном» подходе закономерной становится смена методической парадигмы преподавания языка: от лексикограмматического подхода к эмоционально-смысловому, когда основной целью является успешная коммуникация на иностранном языке [8; 27]. Эти тенденции касаются как методического, так и содержательного плана курса иностранного языка, при этом успехи обучающихся зависят от того, насколько верно преподаватель отвечает их ожиданиям и потребностям [26].

В статье решаются следующие задачи:

- установить цель, задачи и результаты обучения английскому языку пожилых студентов;

- описать ключевые методические принципы обучения английскому языку студентов пенсионного возраста, прошедшие апробацию в ходе реализации проекта «Московское долголетие» в Московском городском педагогическом университете;

- определить базовое содержание и наполнение подобных языковых курсов;

- предложить примерные задания, соответствующие целям и задачам учебной программы, а также уровню и потребностям студентов.

Методами исследования стали анализ педагогических и психологических работ, связанных с изучаемой проблематикой, изучение и обобщение личного педагогического опыта, методы психолого-педагогической диагностики (опрос, анкетирование), рефлексивные методы.

Теоретическую базу исследования составили работы на тему геронтообразования как инновационной социальной практики (Т. М. Кононыгина [15], Н. А. Нагорнова [18], М. В. Ермолаева [11] и др.), возрастных и психологических особенностей пожилых людей (А. Б. Погодина [21], Г. С. Абрамова [2] и др.), а также особенностей преподавания иностранных языков людям пожилого возраста [6; 7; 14].

Практическая значимость исследования заключается в возможности применения полученных результатов в практике преподавания английского языка людям пенсионного возраста, а также при разработке соответствующих образовательных программ и учебных пособий. 


\section{Основная часть}

Идеология системы активного долголетия - жить не только долго, но и быть бодрым, востребованным в обществе, вести активный образ жизни, приобретать новые актуальные знания и навыки. Пилотный проект «Московское долголетие», осуществляемый Правительством Москвы, направлен на то, чтобы помочь людям до 65 лет сохранить здоровье и энергию. Проект предусматривает, что москвичи старшего возраста могут обратиться в центр социального обслуживания, чтобы получить возможность посещать кружок по интересам, и таким образом укрепить здоровье, получить новые знания и умения, творческое развитие. В программу включены самые востребованные направления - спортивные секции, творческие лаборатории и языковые классы, все занятия проводятся бесплатно. Московский городской педагогический университет стал пилотной площадкой в 2017 году, запустив проект «Московский серебряный университет».

Пожилым участникам программы «Обучение и развитие»в МГПУ предлагаются два вида курсов: уроки иностранных языков (в том числе курс «Разговорный английский язык для граждан пенсионного возраста») и цифровой грамотности. Как справедливо отмечают Л. С. Афанасьева и Т. В. Савина [6, с. 141], на этапе знакомства с обучающимися первостепенную важность имеет диагностика - определение не столько языкового уровня, сколько коммуникативных потребностей пожилых студентов и их мотивации, которые будут иметь ключевое значение в плане содержательного наполнения курса. Как показывает наш опыт, в качестве мотивации к изучению английского языка пожилые москвичи чаще всего указывают: 1) необходимость адаптации к новым условиям жизни, преодоление бытового дискомфорта, вызванного непониманием распространённых англицизмов типа кэшбэк, аккаунт, логин, клининг, каршеринг, провайдер, таймер, спред, оверсайз, абьюзер, хайпануть, топовый и др.; 2) путешествия за границей (прочитать меню в ресторане или инструкцию к лекарству, уточнить дорогу в незнакомом городе, совершить покупку в магазине и т.д.); 3) возможность полноценно и беспрепятственно пользоваться ресурсами Интернета, в том числе иноязычными сайтами. Таким образом, целью реализации образовательной программы становится формирование и развитие языковых и речевых навыков, прежде всего навыков разговорной речи в повседневном общении, а также соответствующих речевых умений (восприятие иноязычной речи на слух, догадка по контексту, получение нужной информации от собеседника посредством диалога, участие в дискуссии и т.д.). Задачи реализации программы включают следующее: 1) преодоление языкового барьера и совершенствование уровня разговорного английского языка; 2) улучшение произношения; 3) повышение грамотности разговорной речи; 4) развитие умений и навыков понимания устной разговорной речи носителей иностранного языка (аудирования); 5) расширение словарного запаса, изучение частотных идиоматических выражений и разговорных клише. Планируемые результаты обучения приводятся в таблице ниже.

\begin{tabular}{|c|c|}
\hline \multicolumn{2}{|c|}{ В результате обучения учащиеся будут... } \\
\hline \multirow[t]{3}{*}{ Знать: } & $\begin{array}{l}\text { правила заполнения документов на иностранном языке (миграционные карты, таможенные декларации, } \\
\text { анкеты в отеле и т.д.) }\end{array}$ \\
\hline & культурные особенности и традиции страны изучаемого языка \\
\hline & правила этикета и поведения в странах изучаемого языка \\
\hline \multirow[t]{5}{*}{ Уметь: } & начинать, вести и поддерживать беседу в базовых ситуациях общения \\
\hline & рассказывать о себе, своих интересах, планах на будущее \\
\hline & $\begin{array}{l}\text { расспрашивать собеседника, высказывать свое мнение, отвечать на предложения собеседника согласием } \\
\text { или отказом }\end{array}$ \\
\hline & использовать перифраз, синонимичные средства в процессе устного общения \\
\hline & $\begin{array}{l}\text { понимать короткие устные и письменные тексты (прогнозы погоды, программы телепередач, объявления } \\
\text { в аэропорту, самолете), выделять значимую информацию }\end{array}$ \\
\hline
\end{tabular}

При реализации учебной программы «Серебряного университета» необходимо учитывать возрастные и психологические особенности контингента учащихся: это люди старше 55 лет, большинство из которых уже вышли на пенсию. Как отмечает А. Б. Погодина, в возрастных группах старше 60 лет наблюдается прогрессирующее ухудшение когнитивных функций, являющихся критическими для процесса обучения - памяти и внимания. Так, у пожилых людей отмечается ухудшение функции распределённого внимания (способности фокусироваться на нескольких источниках информации одновременно), увеличивается время обработки перцептивной информации и времени словесно-ассоциативной реакции, имеет место общее снижение способности запоминания (особенно краткосрочная память), память работает избирательно [21]. Кроме того, пожилые студенты часто переоценивают степень снижения своих мыслительных способностей и, боясь совершить ошибку, неосознанно начинают «перестраховываться» - медленнее говорят и читают, стесняются сами инициировать дискуссию на иностранном языке, обратиться к преподавателю за разъяснением. Как следствие, чтобы быть эффективной, практика преподавания английского языка в «возрастных» группах должна следовать определённым методическим принципам.

Принци аппроксимации характерен для преподавания иностранных языков взрослым, находящимся в неязыковой среде, и подразумевает, что если ошибки, допускаемые говорящим, не мешают пониманию его речи слушающим, то такое владение речевыми умениями и навыками следует считать удовлетворительным [4, с. 63]. 
В соответствии с данным принципом преподавателю рекомендуется толерантно относиться к ошибкам, совершаемым возрастными студентами, не корректировать их высказывания по ходу коммуникации, но давать учащимся вербальные поощрения и поддержку во время диалога, самому демонстрировать правильные грамматические и фонетические модели и уделять больше времени их повторению и закреплению. Главная цель коммуникативных заданий - помочь пожилому студенту избавиться от неуверенности и чувства страха перед общением на иностранном языке, поэтому коррекция ошибок является избыточной в ситуации, когда коммуниканты понимают сообщаемую информацию и адекватно реагируют на нее. Также следует отметить отсутствие необходимости в формальном контроле - тестирование полученных навыков и умений целесообразнее проводить в коммуникативной, а не письменной форме, например в виде участия в тематическом диалоге или ролевой игре.

Принци релевантности применим как к содержанию учебного курса, так и к форме подачи материала. Преподаватель должен ориентироваться на практические нужды своих студентов, которые, как уже было отмечено ранее, сводятся к участию в иноязычном повседневном общении на бытовые темы. Соответственно, на первый план выходит развитие диалогических умений студентов, что предполагает постоянное наличие активного собеседника в лице преподавателя (или коллег по группе) и преобладание коммуникативных заданий над пассивным вводом новой лексики и грамматики, а также наличие аутентичных материалов для аудирования, позволяющих преодолеть страх перед восприятием иноязычной речи на слух. Что касается лексического и грамматического наполнения курса, то практика показывает, что для успешной коммуникации хватает прочного знания самых базовых грамматических конструкций и лексики из наиболее актуальных для пожилых людей тематических групп типа «Семья», «У врача», «В ресторане», «Покупки» и т.д. Как отмечают Л. С. Афанасьева и Т. В. Савина, упрощение грамматического и лексического содержания уроков - отсутствие обилия синонимов, похожих фразовых глаголов, сложных глагольных времен и склонений избавляет студентов от необходимости усваивать нерелевантный материал, служит лучшему запоминанию и помогает справиться со страхом перед говорением [6, с. 144].

Принцип цикличности предполагает постоянное повторение изученного материала на более высоком качественном уровне с постепенным включением элементов нового материала [3]. Поскольку «слабым местом» пожилых людей является краткосрочная память, материал каждого урока должен включать активное повторение изученного ранее материала, на который «накладывается» новый. Например, к уже усвоенным выражениям с I have (I have a wonderful family, I have two granddaughters, I have a toy dog и т.д.) прибавляются названия симптомов - I have a sore throat, I have a rash on my stomach, I have pain in my left shoulder.

Принцип доступности в данном случае предполагает доступность учебных пособий, а не общедидактическую установку обучения иностранному языку на доступность и посильность предлагаемого языкового материала. Многие аутентичные учебные пособия могут быть недоступны для пожилых людей в силу высокой цены, поэтому преподавателю следует использовать не более одного такого пособия, при этом будет целесообразно перерабатывать его и дополнять под потребности и особенности возрастного контингента и в соответствии с целями и задачами программы.

Приведем примеры упражнений, используемых на занятиях по английскому языку для москвичей пенсионного возраста на базе Московского городского педагогического университета. Заметим, что упражнения созданы на основе аутентичного учебного пособия и предназначены для продолжающей группы.

Занятие на тему «У врача» предполагает введение большого количества новой лексики, а также повторение уже известной студентам лексики на тему «Части тела» и широкозначных глаголов, ср.: to burn one's hand, to sprain one's ankle, to twist one's wrist, to hurt one's knee, to bang one's head, to have a fever / temperature, to have a rash, to have a headache / toothache / stomachache, to have a pain in (my left shoulder), to have a sore throat, to have the flu / a cold / a tummy bug, to have symptoms, to be ill, to be swollen, to feel (un)well, to feel sick, to feel sore, to feel dizzy, to vomit, to take temperature, to take medicine, to take pills, to get treatment, to get a sunburn, go to hospital, to go to a doctor, to go to a chemist's. В качестве первого упражнения преподаватель может попросить студентов устно перевести короткие предложения, включающие активную лексику и подразумевающие повторение грамматических моментов, ср.: 1) Я плохо чувствовала себя вчера. 2) Сходи в аптеку и купи это лекарство. 3) Доктор померил ей температуру и сказал, что у нее грипп. 4) У меня болит горло, и я пью чай. 5) У него высокая температура и кружится голова. 6) Вася обжег руку и поехал в больницу. 7) В комнате было темно, и Элла ударилась головой. 8) Вчера я упал и вывихнул запястье. 9) Мальчик съел много шоколада, и теперь у него сыпь на животе. 10) Я работала в огороде и повредила колено. 11) Мы были на пляже и получили солнечный ожог.

Следующее упражнение предусматривает аудирование - прослушивание диалога на тему «У врача», после которого студенты должны ответить на вопросы: 1) What are the patient's symptoms? 2) What temperature does he have? 3) What treatment does the patient get?

(Скрипт: Doctor - What seems to be the problem? Patient - I haven't been feeling very well. I was vomiting a lot over the weekend. And I've got this terrible pain in my stomach and a pretty bad headache. I think I've got some kind of tummy bug. Doctor - Does your body feel sore? Patient - Yes, it does. Doctor - OK. I just need to take your temperature. Mmm... 38.5 - you've got a bit of a temperature. You need to drink plenty of tea and stay in bed for the next 48 hours. You also need to take this medicine. You can get it in the chemist's. Just take one pill every six hours. Patient - OK. Thanks a lot. Is there a chemist's near here? Doctor - Yes, there is one right next to the clinic. Patient - Great. Thanks a lot. Bye. Doctor - Bye.)

Далее преподаватель может предложить двум студентам принять участие в небольшой ролевой игре в качестве пациента (роль врача исполняет сам преподаватель или его помощник, у «пациента» на карточке указаны симптомы). Завершающее упражнение предполагает, что группа составляет мини-диалоги на тему «Пациент на приеме у врача», использую активную лексику. 


\section{Заключение}

Стремительный технический прогресс и проникновение англицизмов в язык бытового общения создают трудности для социальной адаптации российских граждан пожилого возраста, снижая уровень социальной комфортности как одного из показателей качества жизни индивида. Создание дополнительных образовательных программ для людей пенсионного возраста, прежде всего бесплатных курсов английского языка на базе педагогических колледжей и университетов, является актуальной задачей, эффективное решение которой будет не только способствовать успешной социализации и адаптации к реалиям цифровой экономики, но и позволит на практике реализовать концепцию непрерывного образования (Lifelong Learning), провозглашающую в том числе активное вовлечение в различные образовательные инициативы именно граждан пенсионного возраста.

Гражданам пожилого возраста важно предложить такой образовательный формат, который позволит продлить их жизненную активность, обеспечить занятость, создать условия для удовлетворения образовательных потребностей и интересов, самореализации, расширения круга общения, и курсы разговорного английского языка идеально вписываются в подобный формат. Преподавание английского языка пожилым людям в рамках неформального обучения предполагает определенные трудности, вызванные возрастными и психологическими особенностями обучающихся. Гарантией достижения поставленных целей обучения могут стать правильно выбранный формат обучения, ориентированный в первую очередь на овладение английским языком как средством повседневного общения, и соответствие программы определенным методическим принципам.

Авторами настоящей статьи на основе имеющегося у них опыта преподавания английского языка людям преклонного возраста в рамках проектов «Московское долголетие» и «Серебряный университет» были сформулированы цель, задачи и результаты реализуемой ими учебной программы, в которой в силу возрастных и мотивационных критериев предпочтение отдаётся развитию умений и навыков разговорной речи, а также пониманию устной разговорной речи носителей английского языка и преодолению психологического блока, называемого «языковым барьером» (страхи, связанные с тем, что пожилой студент не поймет обращенной к нему иноязычной реплики и сам останется непонятым). Кроме того, были определены основные принципы настоящей педагогической практики, опосредованные психофизиологическими особенностями пожилых людей, а также представлены рекомендации по содержанию учебной программы и соответствующие примеры упражнений.

Пожилые студенты нуждаются в индивидуальном подходе, поддержке со стороны преподавателя, толерантном отношении к ошибкам и минимуме критики. Предлагаемый лексический материал и темы для обсуждения должны находиться в соответствии с практическими потребностями контингента курсов (принцип релевантности), постоянно повторяться (принцип цикличности), вводиться с опорой на какие-либо мнемонические техники, упрощающие процесс запоминания, быть доступными и посильными (принцип доступности).

Ключевым методическим принципом (всего авторами их было выделено четыре - принцип аппроксимации, принцип релевантности, принцип цикличности, принцип доступности) является принцип аппроксимации, предполагающий толерантное отношение преподавателя в ходе активной коммуникации к произносительным, грамматическим и лексическим ошибкам пожилых студентов, не влияющим на корректную передачу смысла сообщения говорящим и его интерпретацию слушающим. Главенство данного принципа и необходимость следования ему не вызывают сомнений, так как пожилые студенты, во-первых, изначально не ожидают наличия каких-либо процедур оценивания в неформальном обучении и, во-вторых, болезненно относятся не только к формальным оценкам, но и к критическим замечаниям со стороны преподавателя (выдавая реакции типа «я слишком старый, чтобы это запомнить/освоить»), неизбежно начинают бояться продуцировать спонтанную иноязычную речь.

Научная новизна проведенного исследования заключается в определении ключевых критериев содержания курсов - при наполнении курса, как представляется, необходимо ориентироваться на практические нужды аудитории, преимущественно связанные с бытовым общением в поездках за рубеж. Соответственно, большая часть аудиторных занятий посвящается развитию диалогических умений студентов, коммуникативные задания преобладают над пассивным вводом нового лексико-грамматического материала, необходимо наличие аутентичных образцов иноязычной речи. Упражнения, отрабатываемые на занятиях, должны соответствовать эмоционально-смысловому подходу к изучению иностранных языков и предполагать диалогическое общение студентов с преподавателем и между собой в ходе «разыгрывания» актуальных сценок из повседневной жизни. Кроме того, поскольку обучение возрастных студентов, как правило, проходит в рамках неформального образования, наполнение учебной программы может характеризоваться высокой степенью адаптивности под разные языковые нужды, а преподаватель может предлагать как аутентичный, так и самостоятельно разработанный материал.

\section{Список источников}

1. Абдикеев Н. М. Экономика, основанная на знаниях, и инновационное развитие // Вестник Финансового университета. 2014. № 5. С. 16-26.

2. Абрамова Г. С. Возрастная психология: учебник и практикум для академического бакалавриата. М.: Юрайт, 2014. 811 с. 
3. Алексеева А. М. Цикличность как базовая характеристика организации обучения иностранному языку // Вестник Сургутского государственного педагогического университета. 2013. № 5 (26). С. 196-200.

4. Амирасланова И. А. К вопросу об учете методического принципа аппроксимации в обучении французскому языку в неязыковых вузах с азербайджаноязычным контингентом // Известия Российского государственного педагогического университета им. А. И. Герцена. 2007. № 25. С. 63-66.

5. Асанова Н. И., Талипова Л. Ю., Топеха Т. А. Самообразование как неотъемлемый компонент непрерывного образования: механизмы формирования самообразования // Вестник Пермского национального исследовательского политехнического университета. Социально-экономические науки. 2014. № 3 (24). С. 21-26.

6. Афанасьева Л. С., Савина Т. В. Особенности преподавания английского языка пожилым людям в рамках концепции Lifelong Learning (обучение в течение всей жизни) // Русистика. 2015. № 4. С. 140-145.

7. Высоцкая И. В. Специфика обучения пожилых людей (на примере обучения иностранным языкам) // Современные исследования социальных проблем. 2016. № 11. Ч. 2. С. 52-60.

8. Гальчук Л. М. Основы кросс-культурной коммуникации и менеджмента: практический курс. М.: ИНФРА-М, 2015. $239 \mathrm{c}$.

9. Горохова Н. В., Андросов И. И. Люди третьего возраста в контексте профессионального образования // Вестник Северо-Восточного федерального университета им. М.К. Амосова. Педагогика. Психология. Философия. 2018. № 4 (12). С. 22-25.

10. Дебердеева Т. Х. Проблемы и перспективы развития постдипломного образования в системе непрерывного образования // Образование через всю жизнь: непрерывное образование в интересах устойчивого развития. 2015. Т. 2. № 13. С. 234-238.

11. Ермолаева М. В. Психолого-педагогическое сопровождение пожилого человека: субъектный подход: дисс. ... д. психол. н. М.: Московский психолого-социальный институт, 2010. 507 с.

12. Золотарева Н. М., Рябко Т. В. О приоритетах государственной политики в развитии непрерывного образования взрослых в Российской Федерации // Вестник Южно-Уральского государственного университета. Серия «Образование. Педагогические науки». 2016. № 2. С. 7-10.

13. Казаренков В. И., Казаренкова Т. Б. Высшая школа: самообразование в системе подготовки специалистов // Вестник Российского университета дружбы народов. Серия «Психология и педагогика». 2012. № 2. С. 60-65.

14. Калинина Е. Г. Особенности преподавания иностранного языка пожилым людям // Язык в образовательном пространстве неязыкового вуза: теория и практика: материалы II Всероссийской научно-практической конференции (18-19 апреля 2019 г.). Новосибирск: НГТУ, 2019. С. 81-87.

15. Кононыгина Т. М. Герагогика: пособие для тех, кто занимается образованием пожилых людей. Орел: Агентство печати «Красная строка», 2006. 166 с.

16. Малова И. Ю. Эмоционально-смысловой метод преподавания иностранного языка сегодня // Психология и педагогика: методика и проблемы практического применения. 2010. № 17. С. 394-397.

17. Марон А. Е., Резинкина Л. В. Взрослый в новом обществе и проблемы его саморазвития в условиях непрерывного продуктивного образования // Человек и образование. 2017. № 1 (50). С. 21-25.

18. Нагорнова Н. А. Самоидентификация лиц позднего возраста в условиях адаптивных педагогических систем: автореф. дисс. ... к. психол. н. Самара: Самарский государственный социально-педагогический университет, 2016. 27 с.

19. Непрерывное образование: методология, технологии, управление: коллективная монография / под ред. Н. А. Лобанова, Л. Г. Титовой, В. В. Юдина. Ярославль: РИО ЯГПУ, 2018. 298 с.

20. Об образовании в Российской Федерации [Электронный ресурс]: Федеральный закон от 29.12.2012 № 273-Ф3. URL: http://www.kremlin.ru/acts/bank/36698 (дата обращения: 06.07.2020).

21. Погодина А. Б., Газимов А. Х. Основы геронтологии и гериатрии: учеб. пособие. Ростов-на-Дону: Феникс, 2007. 253 c.

22. Резинкина Л. В. Саморазвитие как ведущий фактор поддержки непрерывного образования взрослых // Человек и образование. 2016. № 3 (48). С. 171-175.

23. Сериков В. В. Непрерывное саморазвитие как профессиональная функция педагога // Образование через всю жизнь: непрерывное образование в интересах устойчивого развития: материалы второго этапа 15-й Международной научно-практической конференции (г. Ярославль, 26-27 сентября 2017 г.). Ярославль: РИО ЯГПУ, 2017. С. 21-25.

24. Скворцов В. Н., Лобанов Н. А. Концепция непрерывного образования и её реализация на базе многоуровневых образовательных учреждений // Вестник ЛгУ им. А. С. Пушкина. 2012. № 4. С. 108-131.

25. Guide on Measuring Human Capital [Электронный ресурс]. URL: https://unstats.un.org/unsd/nationalaccount/ consultationDocs/HumanCapitalGuide.web.pdf (дата обращения: 11.07.2020).

26. James L., Guile D., Unwin L. Learning and Innovation in the Knowledge-based Economy: Beyond Clusters and Qualifications // Journal of Education and Work. 2013. Vol. 26. № 3. P. 243-266.

27. Richards J. C., Rodgers T. S. Approaches and Methods in Language Teaching. Cambridge: Cambridge University Press, 2001. 271 p. 


\section{Информация об авторах | Author information}

RU Иванова Анна Михайловна ${ }^{1}$, к. филол. н. Малыгина Елена Валерьевна ${ }^{2}$ Федорова Елена Дмитриевна ${ }^{3}$

1, 2, 3 Московский городской педагогический университет

EN Ivanova Anna Mikhailovna ${ }^{1}, \mathrm{PhD}$

Malygina Elena Valeryevna ${ }^{2}$ Fyodorova Elena Dmitryevna ${ }^{3}$

1, 2, 3 Moscow City Teachers' Training University

${ }^{1}$ conraoi@yandex.ru, 24cat@mail.ru, 3sssamanta@rambler.ru

Информация о статье | About this article

Дата поступления рукописи (received): 21.08.2020; опубликовано (published): 30.10.2020.

Ключевые слова (keywords): непрерывное образование; активное долголетие; английский язык для взрослых; методические принципы; принцип аппроксимации; принцип релевантности; lifelong learning; active ageing; English for adults; methodological principles; principle of approximation; principle of relevance. 